\title{
Research Note \\ Strain field in straight cylindrical shells due to applied forces on an attached shell. Part I: no hole in the intersection region
}

\author{
A.S. KHAN University of Oklahoma \\ C. HSIAO University of Oklahoma
}

\begin{abstract}
The results of an experimental stress analysis of the intersection region of two straight cylindrical shells are presented. Two models were used; in the first model the two axes were inclined at 30 degrees while for the second case, this angle was 60 degrees. In each case, the main shell was $6.625 \mathrm{in}$. in diameter and $0.198 \mathrm{in}$. thick, while the attached shell was $3.5 \mathrm{in}$. in diameter and 0.226 in. thick. The intersection region was subjected to in-plane and out-plane moments applied to the attached shell and the measurements were made using foil resistance rosette gauges. These measurements demonstrate that the local stress concentration in the intersection region of the main shell increases with the increase of the acute angle between the axes of the two shells; thus for a given moment loading on the attached shell, the stress concentration will be the largest when the two axes are normal to each other.
\end{abstract}

\section{Introduction}

Intersecting cylindrical shell configurations are common in structural components for power and petrochemical plants as well as in off-shore structures. Piping tees and nozzles in cylindrical vessels are some specific examples. Despite their common occurrence, however, proven elastic stress analysis methods have not been generally available and consequently accurate design information for such configurations has also been lacking.

This is especially true for configurations consisting of two intersecting cylindrical shells where the two axes are not perpendicular to each other, even for idealized cases with no transactions, reinforcements, or fillets in the junction region. These configurations are often used to provide restraints on piping systems and pressure vessels in power and petrochemical plants, as well as in off-shore drilling structures.

A comparatively simple configuration where the two cylindrical shells intersect normally has been studied (1)(19) $\dagger$ by several investigators, but with limited results. The theoretical analysis (2)(4) provided rather limited results. Bijlaard (2) converted the moment loading on the attached shell into a pressure loading on the main shell. These calculations were based on a set of equations similar to the well known Flügge equations for a cylindrical shell. The calculation assumed a thin cylindrical shell, simply supported at the ends, loaded by an external pressure in a finite region of the shell. The considered external pressure loading in a region was assumed to result from a thrust or external moment load on the attached shell. The solution to the problem was obtained by representing the displacements and loadings by double Fourier series. Naghdi and Erigen (4) obtained stresses in a shell with a circular cut-out due to internal

The MS. of this paper was received at the Institution on 24 September 1981 and accepted for publication on 8 August 1983.

+ References are given at the end of this note. pressure only. Both investigations ignored the complexities of the intersection region. Erigen and Suhubi (9) included the effect of these complexities, but their analysis was limited to internal pressure loading only (no external moments).

The experimental studies (1)(3)(5)(6) and an experimental and numerical study (9) were more successful but were also limited to intersections of shells with the two axes perpendicular to each other. All of the above experimental studies used electric resistance strain gauges to record the local membrane and bending stresses. These gauges were placed in pairs on the inside and outside of the shell along the centreline meridian and generator around the intersection region. In the study (6) the gauges were also placed in five directions between the centreline meridian and generator directions and thus performed the most detailed study among the experimental investigations. Gwaltney et al. (8) used the same experimental technique as described above. However their study also included a study using a flat plate finite element with five degrees of freedom per node (three translational displacements and two rotations). The agreement between the finite element predictions and the experimental results was shown to be reasonably good.

There appear to be numerous studies on this subject in the proceedings of offshore technology conferences (20)(27). However, most of these investigations, except those of Kuang et al. (24) and Visser (22), do not address the general problem of the effect of the inclination on the stress concentration factors. Almost all of the reported analyses are for the force along the axis of the attached shell as compared to forces applied perpendicular to the axis of the attached shell considered in the present study. The axial force on the attached shell seems to be the limiting case for most offshore structures. However, that is not always the case for other applications; in the case of pressure vessel and piping applications these factors are highest normally for out-of-plane moments, and 
sometimes even for in-plane moments if the diameters of the two shells are of comparable size (3)(5).

As a direct consequence of the above mentioned studies, designs with two shell-type structures are allowed if the axes are perpendicular to each other, since the stress intensification factor is known for this case. In some cases (e.g., design of nuclear power plants) other configurations are allowed only if a detailed analytical analysis or experimental determination of stresses is performed each time, thus discouraging such designs, even though the latter design may be better with respect to stress concentration effect. In the present study the deformation field around the intersection region is determined experimentally when the axes of the two straight cylindrical shells are not perpendicular to each other. Two models are considered. For the first case the angle between the axes is 30 degrees while for the second case it is 60 degrees. The loading consisted of in-plane and outplane forces applied to the attached (smaller diameter) shell. The ends of the main (larger diameter) shell are secured in a thick split plate which in turn is bolted to the main frame. The experimental values obtained in this study are compared to predicted values from semiempirical equations. The empirical relations given by Visser (22) are for axial load on the attached shell, while equations for stress concentration factors, as given by Kuang et al. (24), also include in-plane and out-of-plane moments. These equations are based on parametric finite element study.

\section{The experimental details}

The main and attached shells are made from ASTM 106 Grade B carbon steel. The main shell is 6.625 in. in outer diameter and 0.198 in. thick while the attached shell is 3.5 in. in diameter and 0.226 in. thick. There is no hole in the main shell in the intersection region. After welding, the specimen consisting of two shells is heat treated for one hour at $1200^{\circ} \mathrm{F}$ in order to stress relieve the welds.

The specimen and experimental arrangement is shown in Fig. 1. The ends of the main shell are rigidly clamped to a heavy split plate which in turn is bolted to the main frame. A load in the direction of the axis of the main shell creates in-plane bending in the specimen while the outof-plane moment loading is due to a force perpendicular to the axis of the main shell. These loads are applied to the free end of the attached shell.

All the specimens are instrumented with electrical resistance foil strain gauges on the otuer surface. The gauge locations are shown in Figs 2 and 3. Also shown in the same figures are the type of rosette (consisting of two or three elements), and $\theta$, the angle between the longitudinal vertical plane containing the axes of the two shells and any other vertical plane containing the axis of the attached shell. The two element gauge rosettes are so oriented that they measure the strains in the axial and the circumferential directions of the main shell. The three element rectangular rosettes measure the shear stress as well, and are located in the immediate vicinity of the intersection region where the maximum strains are

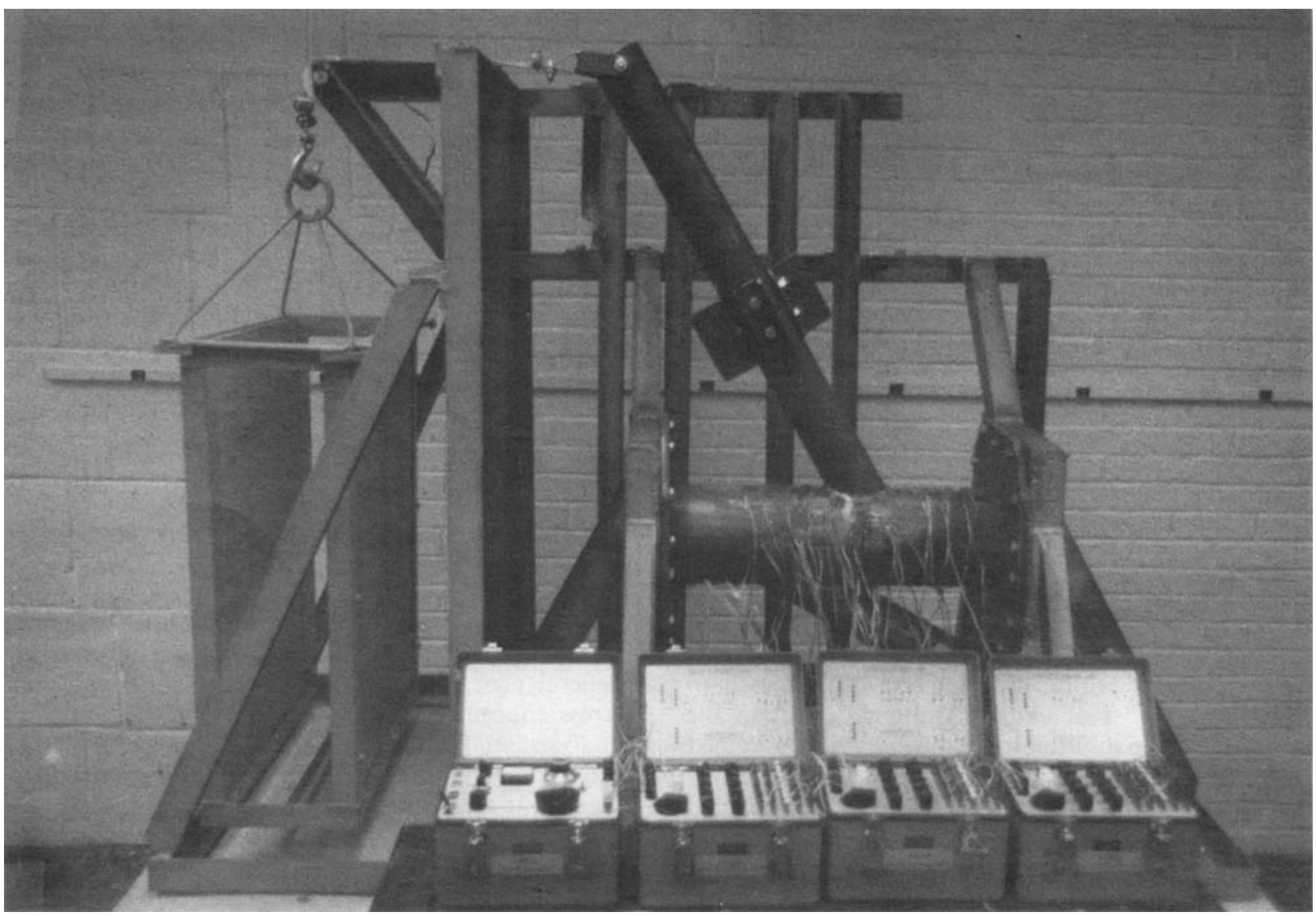

Fig. 1. The experimental arrangement for in-plane loading. A similar arrangement is used for out-of-plane loading, except the applied force is in the direction normal to the plane of the paper 


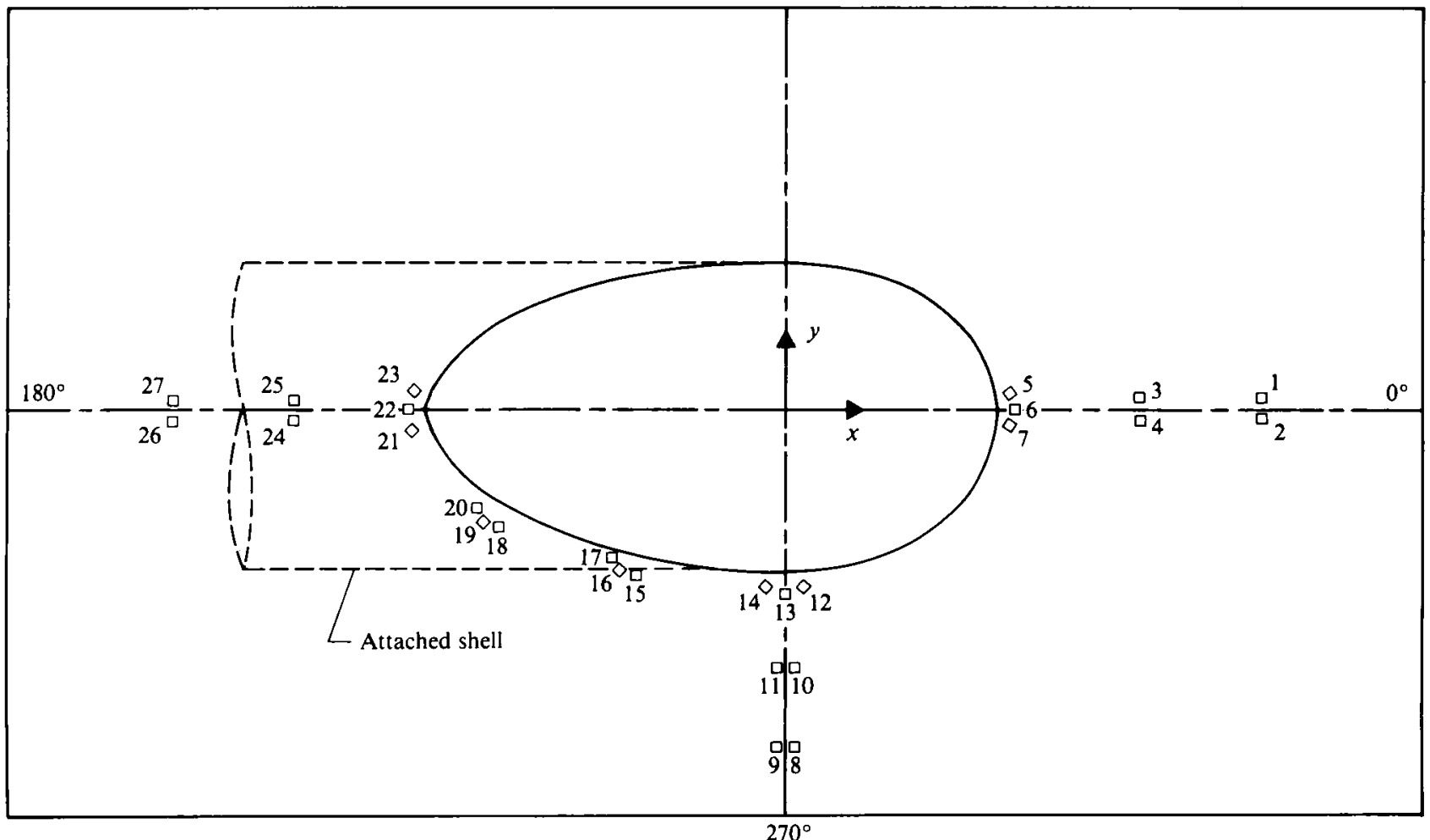

Fig. 2. Developed sketch of the main shell ( 30 degree intersection) and location of the strain gauges

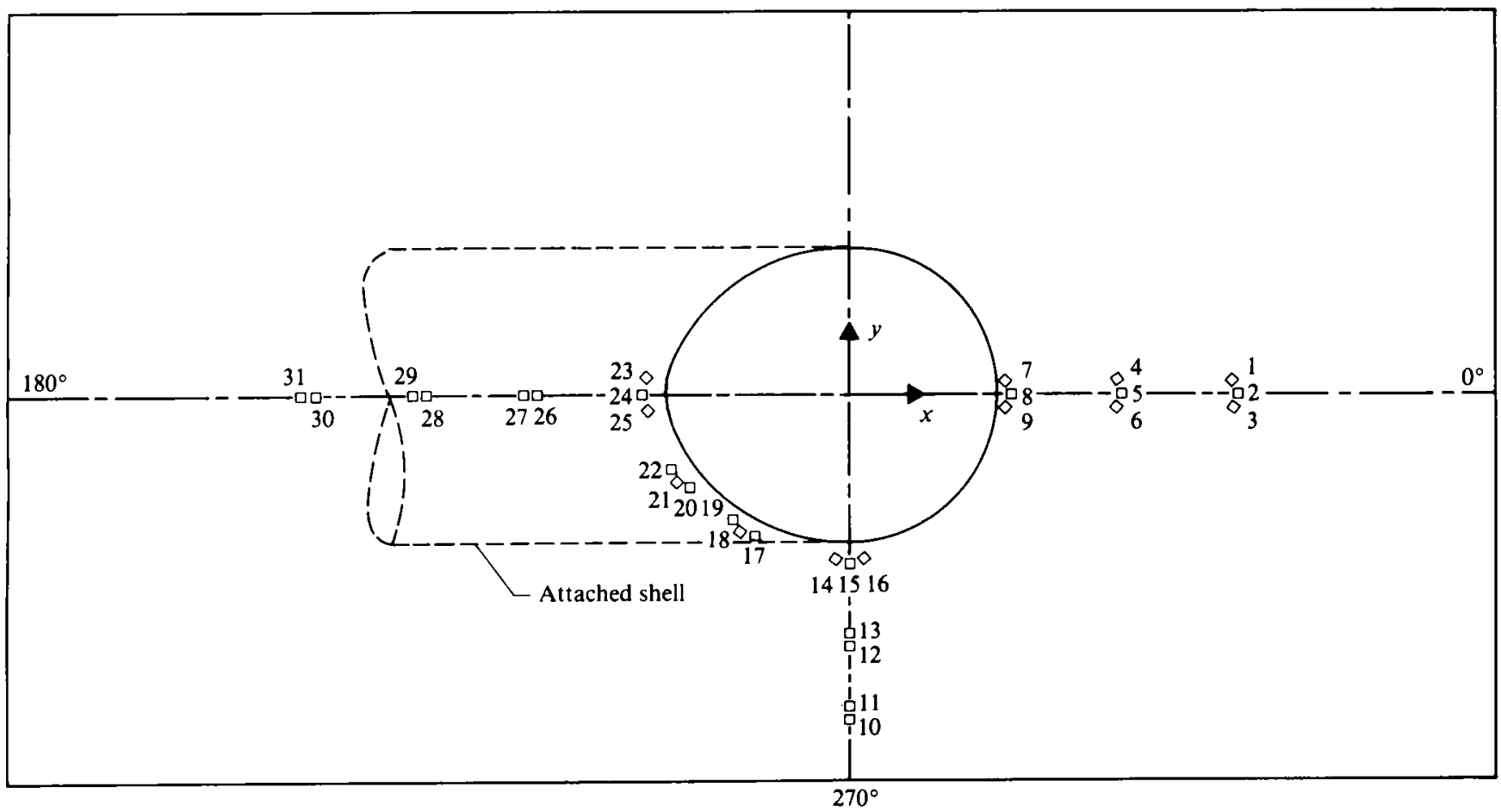

Fig. 3. Developed sketch of main shell (60 degree intersection) and location of the strain gauges 
expected to occur. The gauge locations indicate that a detailed complete strain field is obtained in at least one quadrant of the intersection region (30 degrees apart from each other). The strain gauge data are corrected for the error due to transverse sensitivity of the gauges.

\section{Discussion of results}

The experimental data is converted to stress by using the Young's modulus of ASTM 106 Grade B steel $\left(27.9 \times 10^{6} \mathrm{lb} / \mathrm{in}^{2}\right)$ and a Poisson's ratio of 0.3 . The data in terms of stress is shown in Figs 4-11. The $x$ axis is the local axis at the location of the gauge parallel to the axis of the main shell. Similarly, the $y$ axis is the local axis at the same location in the circumferential direction. The three element rosettes are used in the immediate vicinity of the intersection region where appreciable values of shear stresses are expected. However, the plot of $\tau_{\mathbf{x y}}$ in Figs 5 and 9 shows that the magnitude of these stresses is small even around the intersection region. This justifies the use of two-element rosettes at locations which are not in the immediate vicinity of the intersection region.

In Figs 4-11, the non-dimensional stresses are plotted.

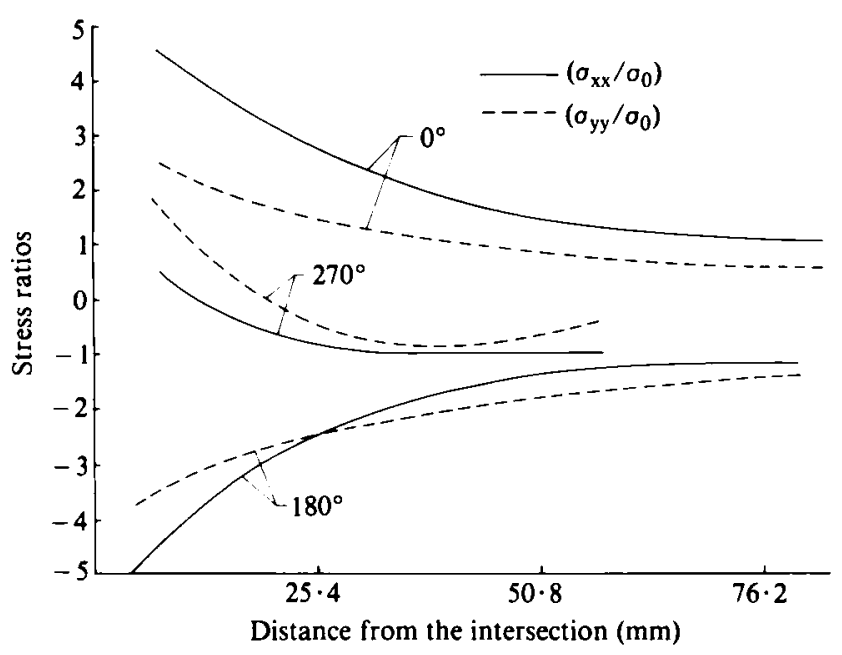

Fig. 4. In-plane loading (30 degree intersection)

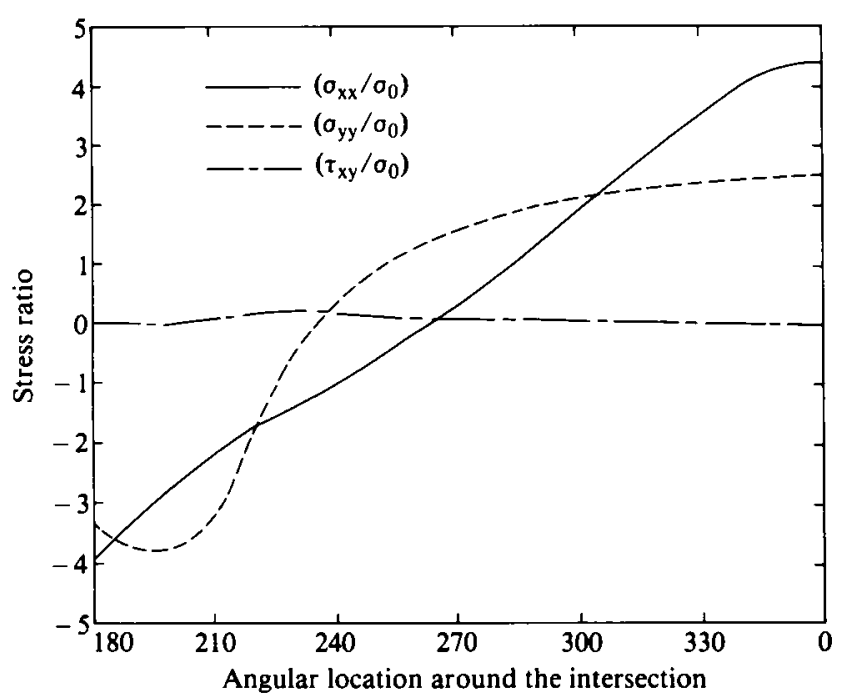

Fig. 5. In-plane loading ( 30 degree intersection)

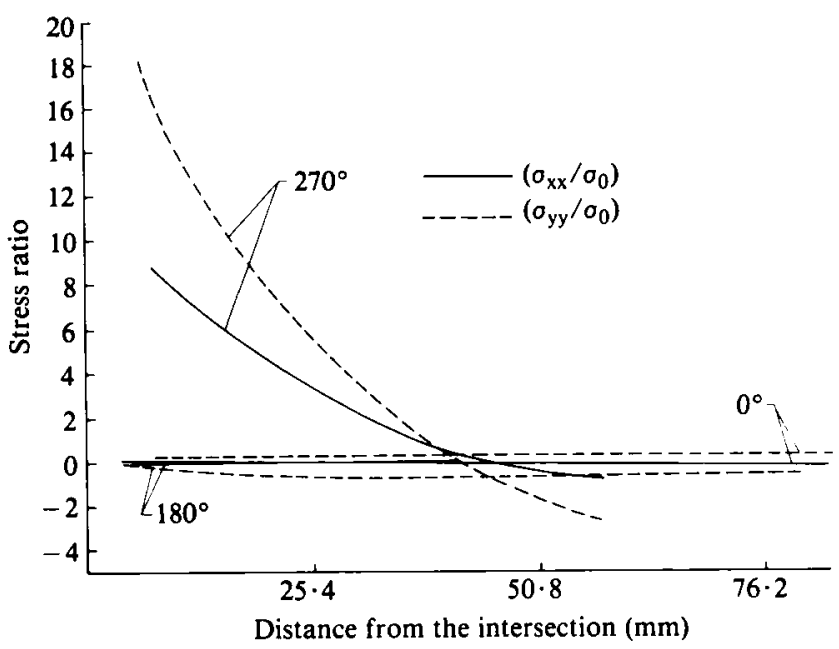

Fig. 6. Out-of-plane loading ( 30 degree intersection)

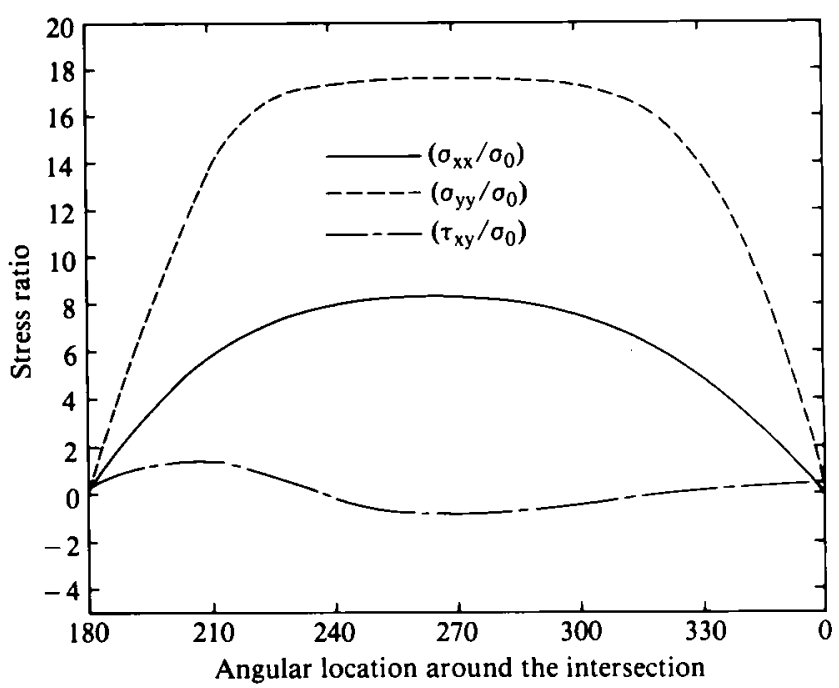

Fig. 7. Out-of-plane loading ( 30 degree intersection)

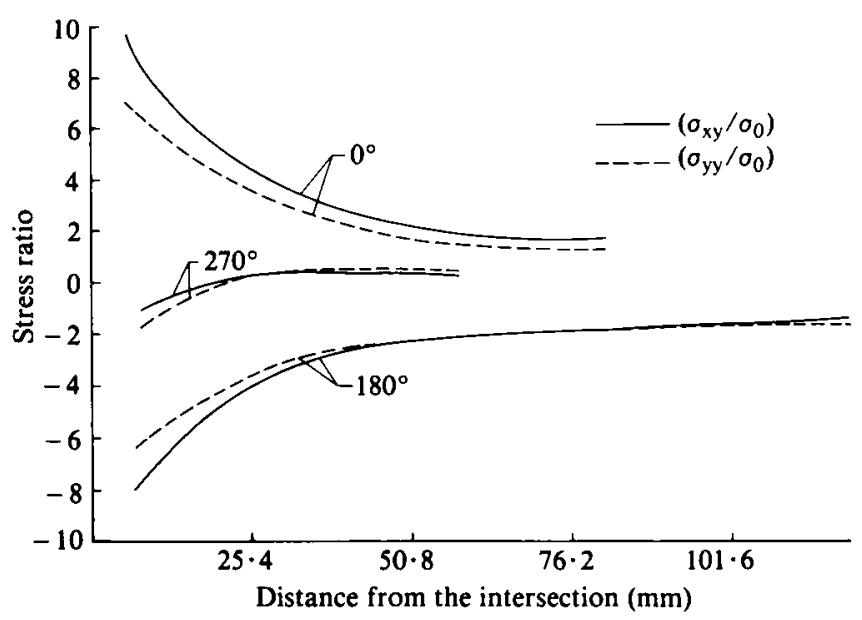

Fig. 8. In-plane loading ( 60 degree intersection) 


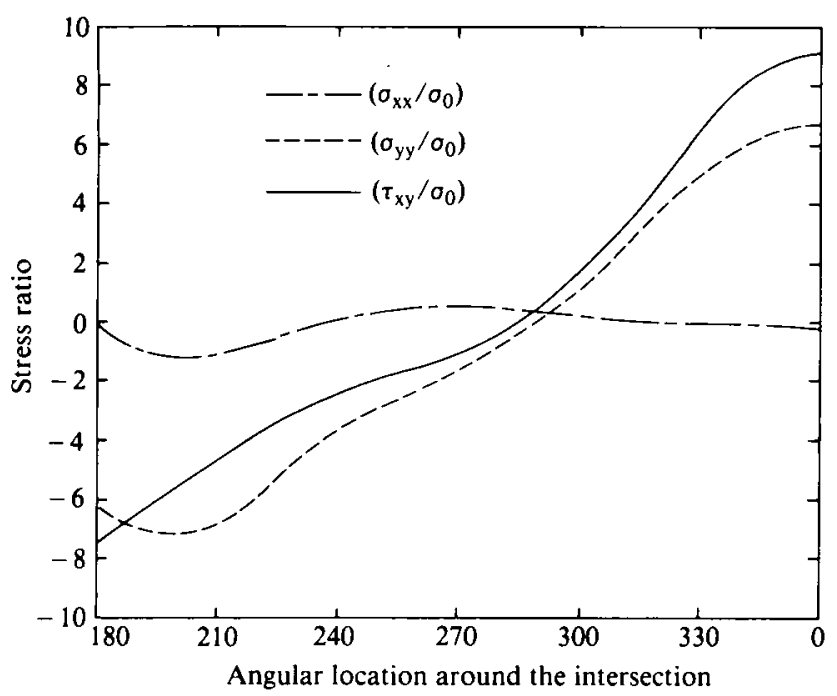

Fig. 9. In-plane loading (60 degree intersection)

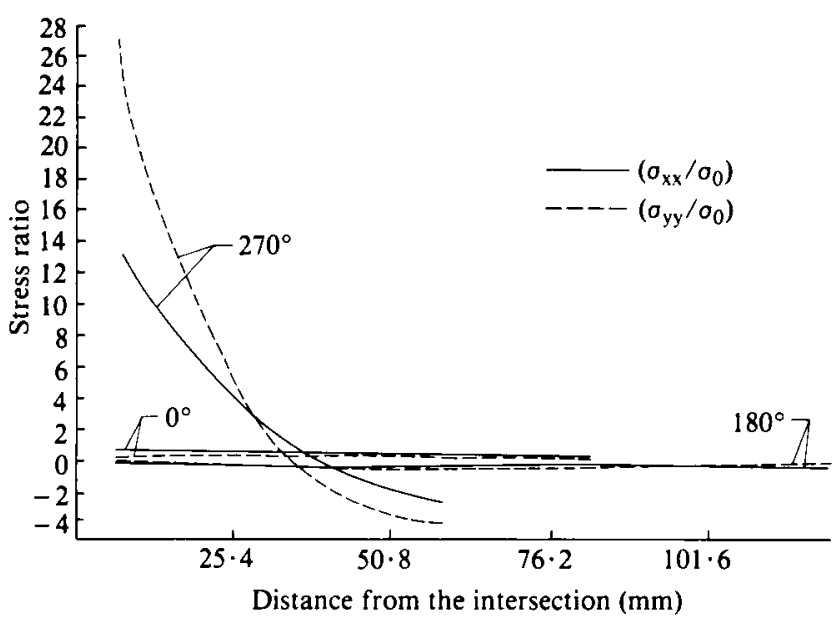

Fig. 10. Out-of-plane loading ( 60 degree intersection)

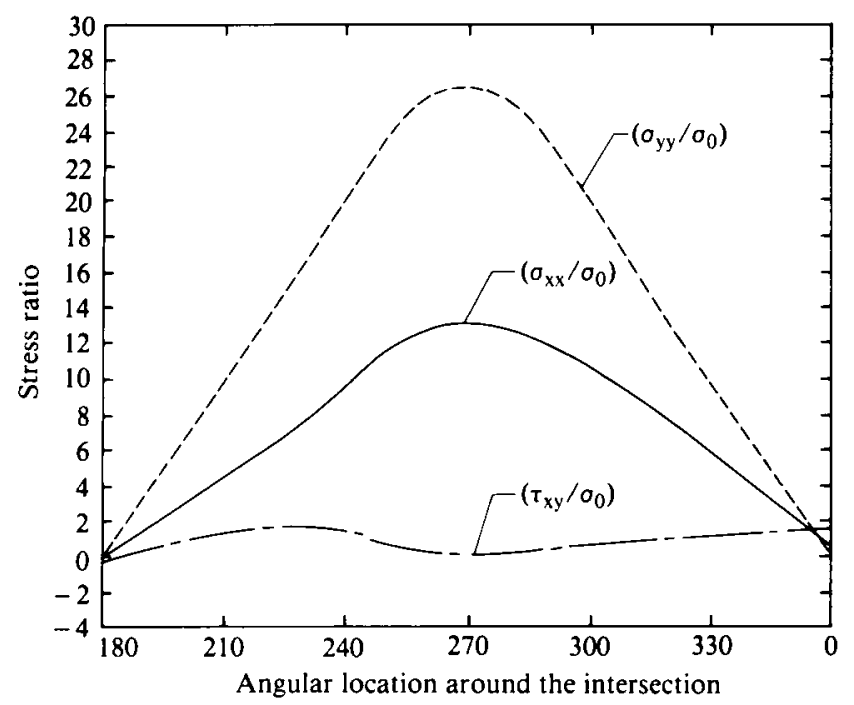

Fig. 11. Out-of-plane loading (60 degree intersection)
This ratio is obtained by the use of 'beam type stress $\sigma_{0}$ ' for the known applied moment $\left(\sigma_{0}=M / Z, M\right.$ being the applied moment and $Z$ the elastic section modulus of the main shell). The magnitudes of the axial stresses are higher than the circumferential stresses along 0 and 180 degrees lines for in-plane bending moments, but the magnitudes are in the opposite order along the 270 degree line. Further, if the stress field for 60 degree intersection is compared with the 30 degree intersection, the magnitudes of the former are 50-100 per cent higher than the latter.

As mentioned earlier, only Kuang et al. (24) address the problem of the effect of inclination on stress concentration factors due to in-plane and out-of-plane moment loads on the attached shell. From a parametric finite element study, they formulated semi-empirical equations (1) and (2) for in-plane and out-of-plane moments, respectively, when the ratio of the attached shell diameter to the main shell diameter is less than 0.55 , and the ratio of thickness $(t / T)$ is less than 0.8 .

$$
\begin{aligned}
& \mathrm{SCF}=0.41(T / D)^{-0.6}(d / D)^{-0.04}(t / T)^{0.86} \sin ^{0.57} \theta \quad(1) \\
& \mathrm{SCF}=0.465(T / D)^{-1.014}(t / T)^{0.889}(d / D)^{0.787} \sin ^{1.557} \theta
\end{aligned}
$$

where

$D, d=$ diameters of main and attached (branch) shell, respectively

$T, t=$ thickness of main and attached (branch) shell, respectively

$\theta=$ acute angle between the axes of the two cylindrical shells

The stress ratios plotted in Figs $4,6,8$, and 10 are based on the nominal stress in the main shell. These values are modified before stress concentration factors are calculated. In Table 1 the values of SCF from the present study based on nominal stress in the branch shell are given. Also shown are the predicted values from equations (1) and (2). Experimental data from two other studies (5)(28) are also included in the same table for comparison. In all cases, the values predicted by equations (1) and (2) are lower than experimental values; in the case of the present study and Cranch's investigation (5), the experimentally determined factors are much higher than the predicted values from these semiempirical relations. It must be mentioned, though, that in the case of the present study and Deacock's analysis (28), the parameters $(t / T)$ are outside the range suggested by Kuang et al.(24).

\section{Conclusions}

It can be concluded from Table 1 that the stress concentration increases as the acute angle between the axes of the two cylindrical shells increases. This result is only for in-plane and out-of-plane loadings. Further, it is observed that the semi-empirical relations based on parametric study, using finite element methods, give predicted values which are much lower than the experimentally determined values. Presumably, some of the difference is due to the fact that in most finite element analyses, the weld, as well as residual stresses due to the weld, are not included in the analyses. 
Table 1. Stress concentration factors for tubular joints

\begin{tabular}{|c|c|c|c|c|}
\hline Joint details & $\begin{array}{c}\text { Angle } \\
\text { (degrees) }\end{array}$ & Loading type & $\begin{array}{c}\text { Experimental SCF } \\
\text { values }\end{array}$ & $\begin{array}{c}\text { Predicted SCF } \\
\text { values } \\
\text { (Kuang et al.) }\end{array}$ \\
\hline Present study & 30 & $\begin{array}{l}\text { in-plane } \\
\text { out-of-plane }\end{array}$ & $\begin{array}{r}5.77 \\
22.83\end{array}$ & $\begin{array}{l}2.6 \\
3.78\end{array}$ \\
\hline Present study & 60 & $\begin{array}{l}\text { in plane } \\
\text { out-of-plane }\end{array}$ & $\begin{array}{l}12.22 \\
35.6\end{array}$ & $\begin{array}{l}3.56 \\
8.89\end{array}$ \\
\hline Present study & 90 & $\begin{array}{l}\text { in-plane } \\
\text { out-of-plane }\end{array}$ & & $\begin{array}{r}3.87 \\
11.12\end{array}$ \\
\hline $\begin{array}{l}\text { Cranch et al. (5), } \\
\quad((R / T)=39.4 \\
(d / D)=0.135 \\
(t / T)=0.6)\end{array}$ & 90 & $\begin{array}{l}\text { in-plane } \\
\text { out-of-plane }\end{array}$ & $\begin{array}{l}288^{*} \\
536^{*}\end{array}$ & $\begin{array}{l}3.93 \\
5.16\end{array}$ \\
\hline $\begin{array}{c}\text { Deacock }(28) \\
\quad(R / T=24.6 \\
(d / D)=0.69 \\
(t / T)=1.0)\end{array}$ & 90 & $\begin{array}{l}\text { in-plane } \\
\text { out-of-plane }\end{array}$ & $\begin{array}{r}8.25 \\
25.17\end{array}$ & $\begin{array}{c}4.3 \\
18.04\end{array}$ \\
\hline
\end{tabular}

* Values taken from Welding Research Council Bulletin No. 198.

\section{References}

(1) SCHESSOW, G. J., and KOOISTRA, J. F., 'Stresses in a cylindrical shell due to nozzle or pipe connections', Trans ASME, 1945, 67, A-107-12.

(2) BIJLAARD, P. P., 'Stresses from local loadings in cylindrical pressure vessels', Trans $A S M E, 1955,77,805-816$.

(3) MEHRINGER, F. J. and COOPER, W. E., 'Experimental determination of stresses in the vicinity of pipe appendages to a cylindrical shell', Proc. Soc. Expl Stress Analysis, 1957, 14(2), 159.

(4) NAGHDI, A. K. and ERINGEN, A. C., 'Stress analysis of a circular cylindrical shell with circular cut out', General Technology Corporation Report No. 3-2, Jan. 1963.

(5) CRANCH, E. T., 'An experimental investigation of stresses in the neighborhood of attachments to a cylindrical shell', Welding Research Council Bulletin No. 60, 1960.

(6) HARDENBERGH, D. E., ZAMRICK, S. Y., and EDMONSON, A. J., 'Experimental investigation of stresses in nozzles in cylindrical pressure vessels', Welding Research Council Bulletin No. 89, July 1963.

(7) BATHE, J. J., WILSON, E. L. and PETERSON, F. E., 'SAP (Structural Analysis Program)', Report No. EERC 73-11, June 1973, College of Engineering, University of California, Berkeley, California.

(8) GWALTNEY, R. C., CORUM, J. M., BOLT, S. E. and BRYSON, J. W., 'Experimental stress analysis of cylinder to cylinder shell models and comparisons with theoretical predictions', J. Pressure Vessel Technol., 1976, 283-290.

(9) ERINGEN, A. C. and SUHUBI, E. S., 'Stress distribution at two normally intersecting cylindrical shells', Nucl. Structural Engng, $1965,2,253-270$

(10) BAKREBAH, S. A. and SCHNOBRICH, W. C., 'Finite element analysis of intersecting cylinders', University of Illinois, Department of Civil Engineering. Structural Research Series No. 400, 1973

(11) BROWN, S. J., 'A finite plate method to solve cylinder-to-cylinder structures subjected to internal pressure', $J$. Pressure Vessel Technol., 1977, 3, 404-412.

(12) HAMSBERRY, J. W. and JONES, N., 'A theoretical study of the elastic behavior of two normally intersecting cylindrical shells', $J$. Engng. Industry, 1969, 3, 563-572.

(13) LEKKERKERKER, J. G., 'The determination of elastic stresses near cylinder-cylinder intersections', Nucl. Engng. Des., 1972, 1, $57-84$.
(14) LIND, N. C., 'Approximate stress concentration analysis for pressurized branch pipe connections', ASME Paper No. 67-WA/ PVP-7, 1967.

(15) MEHRINGER, F. J. and COOPER, W. E., 'Experimental determinations of stresses in the vicinity of pipe appendages to a cylindrical shell', Proc. Soc. Expl Stress Analysis, 1957, 14, 159, 174.

(16) POWELL, G. H. CLOUGH, R. W. and GANTAYAT, A. N. 'Stress analysis of B16.9 tees by the finite element method', ASME Paper No. 71-PVP-40, 1971.

(17) PRINCE, N. and RASHID, Y. R., 'Structural analysis of shell intersections', Proceedings of the Ist International Conference on Pressure Vessel Technology, 1969.

(18) REDEKOP, D., 'Three-dimensional analysis of an elastic platecylinder intersection by the boundary-point-least-squares technique', J. Pressure Vessel Technol., 1977, 99, 17-24.

(19) ROSE, R. T., 'Stress analysis of nozzles in thin walled cylindrical pressure vessels', Br. Welding J., 1965, 12, 80-90.

(20) KWAN, C. T., and GRAFF, W. J., "Analysis of tubular Tconnections by the finite element method: comparisons with experiments', Proc. Offshore Technol. Conf., Houston, 1972, pp. 487-496.

(21) GRIEMANN, L. F., et al., 'Finite element analysis of complex joints', Proc. Offshore Technol. Conf., Houston, 1973, pp. 877-889.

(22) VISSER, W., 'On the structural design of tubular joints', Proc. Offshore Technol. Conf., Houston, 1974, pp. 881-894.

(23) MILLER, C. D. and TRAMMELL, J. H., 'An analytical and experimental study of stiffened tubular joints with multiple branches', Proc. Offshore Technol. Conf., Houston, 1974, pp. 677685.

(24) KUANG, J. G., et al., 'Stress concentrations in tubular joints', Proc. Offshore Technol. Conf., Houston, 1975, pp. 593-612.

(25) LIAW, C. Y., et al., "Improved finite elements for the analysis of welded tubular joints', Proc. Offishore Technol. Conf., Houston, 1976 , pp. 267-282

(26) OHTAKE, F., et al., 'Static and fatigue strength of high tensile strength steel tubular joints for off-shore structures'. Proc. Offshore Technol. Conf., Houston, 1978, pp. 1747-1755.

(27) REIMER, R. B., et al., 'Finite element analysis of complex welded tubular joints', Proc. Offshore Technol. Conf., Houston, 1979, pp. $153-167$.

(28) DECOCK, J., 'External loadings on nozzles in cylindrical shells', Fourth International Conference on Pressure Vessel Technology, 1980, (Institution of Mechanical Engineers, London) Vol. 2, pp 127-134. 